\title{
Dollar Index Adjusted Stock Indices
}

\author{
Terrance Jalbert, University of Hawaii at Hilo, USA
}

\begin{abstract}
This paper presents stock indices that reflect changes in both stock value and underlying currency value. An earlier study develops the first known currency adjusted stock index. This paper extends the literature by utilizing a better measure of US dollar value to develop currency value adjusted indices. We examine distributional properties of the indices and determine the portion of wealth change attributable to stock value change and currency value change. The results show significant differences in return variance between original and dollar adjusted indexes. The results further show that changes in the stock index level explain most wealth changes. However, changes in currency value explain as much as 14.9 percent of wealth changes.
\end{abstract}

Keywords: Stock Index; Currency Value; Currency Value Adjusted Stock Index

\section{INTRODUCTION}

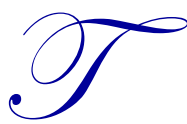

he use of indices to evaluate stock performance dates to at least the 1800's. Many indices exist to track market segments. The domestic currency represents the underlying basis for the indices. The indices do not reflect the purchasing power of the underlying currency. This practice does not present a problem if the underlying currency value is stable. However, if the underlying currency value is unstable, the index does not accurately reflect wealth changes. An investor who observes a one percent stock index increase believes they have experienced a wealth increase. However, the stock index increase, accompanied by a two percent decrease in the underlying currency value, implies the investor has experienced a net wealth decline. An investor who examines only stock index changes makes an incorrect inference.

Many individuals invest or live outside their country of citizenship. Indeed the number of U.S. citizens living abroad has increased dramatically in recent years. The precise number of U.S. citizens living abroad is unknown. However, 2013 U.S. State Department estimates indicate some 7.6 million U.S. citizens live outside the U.S. (Bureau of Consular Affairs, U.S. Department of State, 2013). A 2004 State Department figure places the number of U.S. citizens living abroad at 3.2 million (Bureau of Resource Management, U.S. Department of State, 2004). Thus, the number of U.S. citizens living abroad more than doubled over a nine-year period. Despite living abroad, many individuals continue to invest in the U.S. They must convert their U.S. investments to the currency in their domicile country for consumption needs. These individuals have an interest in the purchasing power of U.S. investments in their domicile country.

Other individuals also have an interest in the performance of their investments on an international market. Individuals within the U.S. purchase foreign produced products. Prices of these foreign products vary with the U.S. dollar value. Individuals have an interest in the ability of their U.S. investments to purchase these items. Still other individuals travel abroad. The U.S. Department of State estimates that 65 million U.S. citizens travel abroad annually (Bureau of Consular Affairs, U.S. Department of State, 2013). These individuals will spend some of their wealth in foreign countries and are interested in the extent that their investments can support their purchase plans.

Stock indices use varying combinations of index components and computation methods to arrive at their values. In each case, these indexes report values based on the domestic currency. Currency adjusted stock indices provide a measure of combined wealth effects. These indices reflect changes in both stock and currency values.

Jalbert (2012) developed the first known currency value adjusted indices. His indices use eight existing U.S. stock indexes combined with two measures of U.S. dollar value. He uses the Major and Broad measures of currency value available from the U.S. Federal Reserve. This approach has the advantage of providing the longest data time series for analysis. However, the approach suffers from three limitations. The Federal Reserve 
periodically retroactively adjusts the methodology and components used in the index computations. These adjustments cause issues in developing an index for use and evaluation over long periods. Second, intraday data is not available for the Federal Reserve data, limiting any index based on this data to end-of-day values. Third, news outlets do not readily report the Federal Reserve indices thereby limiting investor familiarity.

This paper extends the work of Jalbert (2012) in two ways. First, the work here includes nearly two years of new data. Jalbert (2012) used data through July 2011. The data used in this study extends through April 2013. Second, like Jalbert (2012), we examine eight major U.S. stock indices. However, this paper uses a different measure of currency value. This paper uses Dollar Index (DXY) data. The Dollar Index equals a geometric mean of six currencies used to determine the U.S. dollar value: Euro (57.6\%), Yen (13.6\%), Great Britain Pounds Sterling (11.9\%), Canadian Dollar (9.1\%), Swedish Krona (4.2\%) and Swiss Franc (3.6\%). The index started in March of 1973 with a value of 100. Higher index levels imply a strong dollar. Lower index levels indicate a weak dollar. The index reached levels as high as 164.72 in February 1985 and as low as 70.698 on March 16, 2008. The Intercontinental Exchange features a futures contract on the index. The index is also available in options, exchange traded funds and mutual funds. Koch (2013) criticizes the index in large part based on the basket of currencies included in the computations and currency weightings. Nevertheless, the index has the advantage of intraday quotations, it is widely reported and has options and futures contract availability. Because of these advantages, the indices created here present a more viable index alternative relative to the work of Jalbert (2012).

In the next section, we provide a review of the extant of literature. Next, we discuss the data and methodology. The following section presents the empirical test results. The paper closes with some concluding comments and suggestions for future research.

\section{LITERATURE REVIEW}

A sizable literature examines stock indexes. However, only a single prior paper on currency value adjusted stock indexes exists. Thus, we relate the research here to the general literature on stock indexes. Existing literature on stock indexes follows different streams. These literature streams include examinations of the relationship between stock indexes and stock index futures and options contracts, stock index volatility and the price and return reactions of firms added to and deleted from stock indexes.

If an index is predictable, investors can time the market to earn abnormal returns. Alvarez-Ramirez and Rodriguez (2011) identify recurrent cycles in the Dow Jones Industrial Average (DJIA). They find cycles between 4.5 and 22 years in length. The 2010 downturn coincides with a 22-year DJIA cycle. Wong, Lian and Cheong (2009) find the DJIA has volatility phases. They find that index changes follow a Gaussian process with some 116 stationary segments. Opong, Mulholland, Fox and Farahmand (1999) examine distribution properties of the London Financial Times Stock Exchange, All Share index. They find cycles occur more often than expected under a random series. They find a Generalized Autoregressive Conditional Heteroskadisticity process best explains the index series.

Lakonishok and Smidt (1998) examine seasonality patterns in the DJIA over a ninety-year period. They find evidence of persistent turn of the week, month, year and holiday return anomalies. Donaldson and Kim (1993) examine price barriers in the DJIA. They find support and resistance levels around index level multiples of 100. They identify disproportionate moves when an index breaks through a barrier. Recent research uses neural networks and hybrid models to predict stock index levels (Ferreira, Vasconcelos \& Adeodato, 2008).

Breen, Glosten and Jagannathan (1989), examine the economic significance of variations in stock index returns. They find one-month interest rates can forecast the sign and variance of stock index excess returns. Martens, van Dijk and de Potter (2009) model the ability of macroeconomic effects to forecast S\&P 500 Index volatility. The incorporation of macroeconomic effects into their model produced improved out-of-sample forecast accuracy for twenty-day-ahead forecasts.

Many options and futures products related to stock indices exist. If incorrectly priced, these products can produce arbitrage opportunities. Taylor (2007) develops an econometric model of mispricing associated with futures and spot price differences. He shows that S\&P 500 arbitrageurs prefer middle of the day trades. Hora and 
Jalbert (2006) examine DJIA Index Options pricing. They examine distribution characteristics of the DJIA over a 100 -year period. The results lead them to propose a derivation of the Black and Scholes option-pricing model based on the Student t-distribution (Black \& Scholes, 1973). Their adjusted valuation model prices index options more accurately than the Black and Scholes model.

Stock index volatility measures risk of index changes. Many articles examine stock index volatility. French and Roll (1986) identify higher stock price volatility when stock exchanges are open. Several articles relate volatility changes to macroeconomic variables. Some potential macroeconomic explanatory variables include time varying volatility and financial leverage (Christie, 1982), expected stock return changes (Merton, 1980; Bollerslev, Engle \& Wooldridge, 1988) and interest rates (Lauterbach, 1989).

A recent literature examines the effects of stock index additions and deletions. The findings show that prices of stocks added to an index increase. Similarly, prices of stocks deleted from an index decline (Shleifer, 1986, Beneish \& Gardner, 1995). Chen, Noronha and Singal (2006) examine arbitrage activity around index changes. Their findings show that index change arbitrage exists. They find that S\&P 500 and Russell 2000 index fund investors collectively lose as much as $\$ 2.1$ billion annually due to index change arbitrage. Jankovskis (2002) argues that flaws exist in the Russell 2000 rebalancing procedure. His results show a 1.2 percent annual downward bias in index returns due to rebalancing. Liu (2011) argues that higher investor awareness and reduced price volatility explain price increases associated with stocks added to indices.

As noted earlier, Jalbert (2012) provides the only known article to introduce currency value adjusted stock indices. He computes currency adjusted indices based on eight existing U.S. stock indices. The results show marked differences in unadjusted and adjusted index levels as well as daily and annual returns. He finds that unadjusted and adjusted index annual returns for the Dow Jones Industrial Average differ by as much as 18.211 percent. Daily return signs are different on 12.99 percent of all trading days, indicating the unadjusted index indicates a positive (negative) return, but the adjusted index indicates a negative (positive) return. The results further show that adjusted and unadjusted indices have different distribution properties. Finally, he finds currency value changes explain as much as 8.44 percent of total wealth changes.

\section{DATA AND METHODOLOGY}

We obtained time series data from EODData, which publishes historical daily data on economic time series. Daily data were available from January 1, 1993 through April 12, 2013. We collected data for the Dollar Index (DYX) and eight market indices. The market indices include the Dow Jones Industrial Average (DJI), Dow Jones Transportation Index (DJT), Dow Jones Utilities Index (DJU), Standard and Poor's 500 (SP500), Russell 3000 (RUA), Russell 1000 (RUI), NASDAQ 100 (NDX) and NYSE Composite (NYA). We eliminated Saturday trading data from the Dollar Index data to synchronize data with the other series. We also eliminated reported data on nontrading days from the stock index series. The final dataset includes 5,107 daily observations for each series.

This research calculates the Dollar Index adjusted series, $D A S_{t}$, by modifying each existing stock index, $O I_{t}$, with Dollar Index information, $D I_{t}$, as shown in Equation 1:

$D A S_{t}=O I_{t} * \frac{D I_{t}}{100}$

To demonstrate the use of Equation 1, consider an unadjusted index with level of 5,000. The Dollar Index equals 103. Then the adjusted index level equals 5,150. When the Dollar index equals 100, the raw and adjusted stock indices will equal. When the Dollar index exceeds 100, the adjusted index level exceeds the raw index. Dollar Index levels below 100 imply an adjusted index less than the raw index.

Figure 1 shows the time series progression of the Dollar Index from 1993 through 2013. The chart shows Dollar Index levels below 100 for most of the period examined. The index approached or exceeded 100 for the period March 26, 1999 through April 11, 2003. Prior to March 26, 1999 and after April 11, 2003 the index remained below 100 . As noted earlier, higher index levels imply a more valuable dollar, while lower index levels imply a less valuable dollar. 


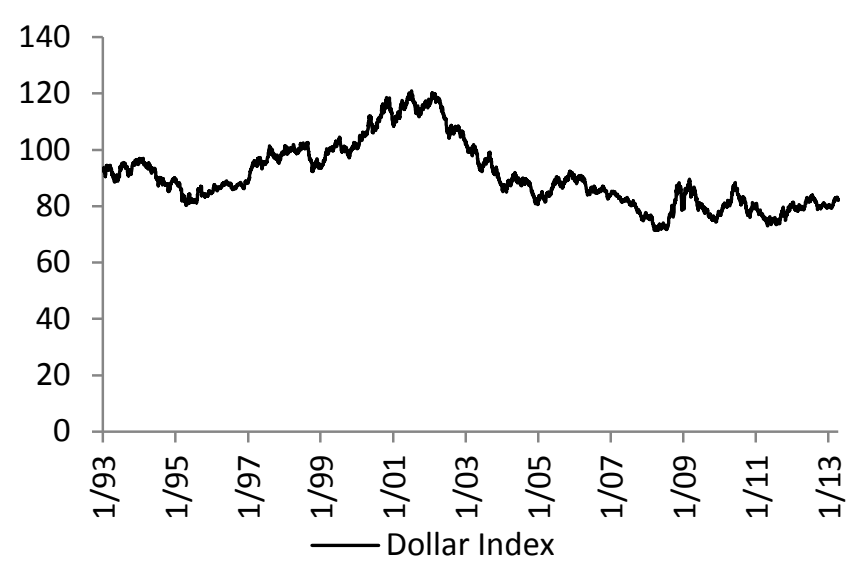

Figure 1: Dollar Index Levels

Figure 1 provides a time series depiction of Dollar Index levels. The index started in March of 1973 with an initial value of 100. Index levels above 100 indicate a strong dollar relative to March 1973 levels. Index levels below 100 indicate a weak dollar relative to 1973 levels.

Table 1: Descriptive Statistics

\begin{tabular}{|c|c|c|c|c|c|c|c|c|c|}
\hline \multicolumn{10}{|c|}{ Panel A: Raw Indices } \\
\hline & DJIC & DJTC & DJUC & SP500 & NDX & RUA & RUI & NYA & DXY \\
\hline Mean & $9,282.958$ & $3,319.512$ & 329.510 & $1,059.352$ & $1,567.164$ & 603.710 & 569.434 & $6,177.094$ & 90.823 \\
\hline Median & $10,164.920$ & $3,070.130$ & 314.870 & $1,129.440$ & $1,528.150$ & 639.750 & 604.450 & $6,484.720$ & 88.260 \\
\hline Maximum & $14,865.140$ & $6,281.240$ & 552.740 & $1,593.370$ & $4,704.730$ & 947.170 & 884.237 & $10,311.610$ & 120.900 \\
\hline Minimum & $3,241.950$ & $1,372.530$ & 167.570 & 429.050 & 327.280 & 246.090 & 229.910 & $2,497.620$ & 71.370 \\
\hline Std. Dev. & $2,897.905$ & $1,191.900$ & 98.050 & 318.027 & 816.157 & 183.783 & 174.181 & $1,979.775$ & 11.469 \\
\hline $\mathrm{C} / \mathrm{V}$ & 0.3122 & 0.3591 & 0.2989 & 0.3002 & 0.5208 & 0.3044 & 0.3059 & 0.3205 & 0.1263 \\
\hline Skewness & -0.641 & 0.287 & 0.279 & -0.6090 & 0.6878 & -0.5211 & -0.5501 & -0.2854 & 0.705 \\
\hline Kurtosis & -0.531 & -1.014 & -1.070 & -0.7270 & 0.6877 & -0.7839 & -0.7743 & -0.7041 & -0.218 \\
\hline $\begin{array}{l}\text { Jarque- } \\
\text { Bera }\end{array}$ & $409.96 * * *$ & $288.96 * * *$ & $310.10^{* * *}$ & $428.09 * * *$ & $502.47 * * *$ & $361.85 * * *$ & $385.13 * * *$ & $174.92 * * *$ & $432.67 * * *$ \\
\hline Obs. & 5,107 & 5,107 & 5,107 & 5,107 & 5,107 & 5,107 & 5,107 & 5,107 & 5,107 \\
\hline \multicolumn{10}{|c|}{ Panel B: Dollar Index Adjusted Indices } \\
\hline & DJI & DJT & DJU & SP500 & NDX & RUA & RUI & NYA & \\
\hline Mean & $8,372.718$ & $2,943.950$ & 294.526 & 960.580 & $1,426.101$ & 545.568 & 515.337 & $5,546.613$ & \\
\hline Median & $8,947.180$ & $3,046.810$ & 298.443 & 984.275 & $1,332.768$ & 564.668 & 529.753 & $5,865.225$ & \\
\hline Maximum & $13,248.646$ & $5,190.047$ & 471.161 & $1,720.542$ & $4,955.963$ & 949.576 & 918.544 & $8,290.533$ & \\
\hline Minimum & $2,969.302$ & $1,228.826$ & 150.750 & 383.726 & 289.676 & 219.000 & 204.732 & $2,245.269$ & \\
\hline Std. Dev. & $2,620.741$ & 876.936 & 77.358 & 312.539 & 818.875 & 171.944 & 166.328 & $1,677.910$ & \\
\hline $\mathrm{C} / \mathrm{V}$ & 0.3130 & 0.2988 & 0.2627 & 0.3254 & 0.5742 & 0.3152 & 0.3228 & 0.3025 & \\
\hline Skewness & -0.6618 & -0.2570 & 0.0058 & -0.1614 & 1.4034 & -0.3122 & -0.2362 & -0.6208 & \\
\hline Kurtosis & -0.5048 & -0.7812 & -0.9542 & -0.4811 & 3.0714 & -0.5672 & -0.5194 & -0.6706 & \\
\hline $\begin{array}{l}\text { Jarque- } \\
\text { Bera }\end{array}$ & $426.90 * * *$ & 186.17 *** & $193.88 * * *$ & 71.56 **** & $3,677.32 * * *$ & $151.54 * * *$ & $105.02 * * *$ & $423.66^{* * * *}$ & \\
\hline \multicolumn{10}{|c|}{ Panel C: Equality Tests } \\
\hline & DJI & DJT & DJU & SP500 & NDX & RUA & RUI & NYA & \\
\hline Mean & $277.17 * * *$ & 328.97 *** & $400.72 * * *$ & $250.59 * * *$ & $76.03 * * *$ & $272.56 * * *$ & $257.66^{* * *} *$ & $301.42 * * *$ & \\
\hline Median & $20.22 * * *$ & $12.73 * * *$ & $16.74 * * *$ & $19.59 * * *$ & $12.63 * * *$ & $19.44 * * *$ & $19.31 * * *$ & $18.42 * * *$ & \\
\hline Std. Dev. & $47.97 * * *$ & $525.77 * * *$ & $445.71 * * *$ & $11.73 * * *$ & $33.55^{* * * *}$ & $41.44 * * *$ & $27.07 * * *$ & $129.17 * * *$ & \\
\hline
\end{tabular}

This table shows descriptive statistics for the sample. Notations are as follows: Dow Jones Industrial Average (DJI), Dow Jones Transportation (DJT), Dow Jones Utilities (DJU), Standard and Poor's 500 (SP500), Russell 3000 (RUA), Russell 1000 (RUI), NASDAQ 100 (NDX), NYSE Composite (NYA) and Dollar Index (DXY). The Welch F-test (1951) test identifies significant differences in means and the Mann-Whitney (1947) test identifies significant differences between medians. The Brown and Forsythe (1974) test identifies differences in variance. $* * *$ indicate significance at the 1 percent level.

Table 1 shows summary statistics of the raw and adjusted indices. Panel A shows the results for the original indices, without adjustment and of the Dollar Index series. Panel B shows the results for the Dollar Index adjusted indices. The Jaque-Bera goodness of fit test identifies deviations of a series from a normal distribution 
(Jarque and Bera, 1980). The results indicate that each series, both original and adjusted, deviates significantly from a normal distribution. The standard deviation is lower for the adjusted indices. This finding is not surprising as the means differ. To gain additional insights, we compute the coefficient of variation, $C V$, which shows the amount of standard deviation for each unit of mean, using the following formula:

$C V=\frac{\text { Standard Deviation }}{\text { Mean }}$

The CV results indicate considerable differences between the relative variance of the original and adjusted indices. For example, the original NASDAQ $100 \mathrm{CV}$ equals 0.5208 while the adjusted series CV equals 0.5742 , a difference of 0.0534 equaling about 10.25 percent of the NASDAQ $100 \mathrm{CV}$. For some index pairs, the original index has higher $\mathrm{CV}$, and for other index pairs the adjusted index has higher $\mathrm{CV}$.

Panel C shows results of tests for equality. These tests involve comparing each unadjusted index to its Dollar Index adjusted counterpart. We use the Welch F-test (1951) test to identify differences in means and the Mann-Whitney (1947) test to identify differences between medians. We use the Brown and Forsythe (1974) test to identify differences in variance. The results show significant mean, median and standard deviation differences for each index pair. We further explore this issue in return form later in the paper.

The charts in Figure 2 show the pairwise progression of each original index, along with its dollar value adjusted counterpart. The results show considerable differences between the two indices. The differences become more evident after the year 2000. The results show the adjusted indices track below the unadjusted indices for most of the period examined and continuously since April 11, 2003.

Figure 2 shows the time series of original and Dollar Index adjusted indices. DJI, DJT, DJU, DJIA, DJTA and DJUA indicate the original and adjusted Dow Jones Industrial Average, Dow Jones Transportation Average and Dow Jones Utilities Average indices respectively. SP500 and SP500A indicate the original and adjusted Standard and Poor's 500 index respectively. NDX and NDXA indicate the original and adjusted NASDAQ 100 indices respectively. RUA, RUI, RUAA and RUIA indicate the original and adjusted Russell 3000 and Russell 1000 indices respectively. NYA and NYAA indicate the original and adjusted NYSE Composite indices respectively. 

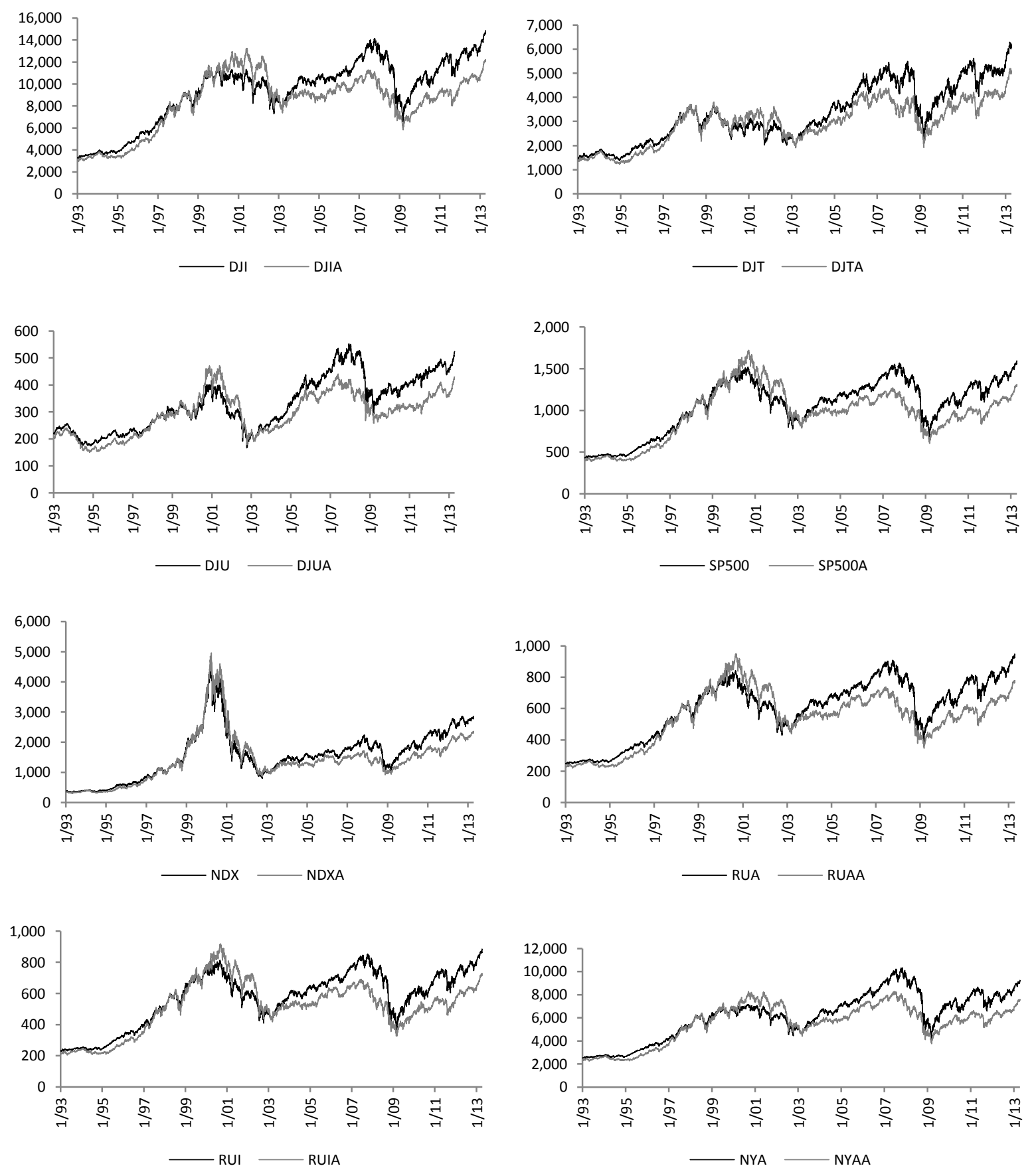

Figure 2: Time Series of Raw and Currency Index Adjusted Indices

\section{RESULTS}

This section presents the empirical results. We begin with an analysis of daily returns. Consider an index with level, Index Level $_{t}$ on day $t$ and Index Level $_{t-1}$ on day $t-1$. Equation 3 shows the computation methodology for the continuously compounded daily return on day $t, C C R_{t}$, as follows:

$C C R_{t}=\ln \left(\frac{{\text { Index } \text { Level }_{t}}_{\text {Index Level }} t-1}{\text { Ind }}\right)$ 
We complete daily return calculations for each original index and each adjusted index. Next, we examine the returns to identify original and adjusted indices agreement on the direction of change for a given day. The results are presented in Table 2. Table 2, Column 3 shows the number of observations where the original and adjusted indices agree on the sign of change. For the Dow Jones Industrial Average (DJI), the original and adjusted indices both indicate a positive return or both indicate a negative return for 4,264 trading days. Similarly, Column 4 shows the number of observations where the original and adjusted indices disagree. For the DJI, the original and adjusted indices disagree on 842 trading days. On these days, one index indicates a positive return while the other index indicates a negative return. Columns 5 and 6 show the percentage of trading days with return sign agreement and disagreement respectively. The highest agreement level occurs for the NASDAQ 100 at 88.97 percent agreement. The lowest agreement level occurs for the NYSE Composite, at 82.86 percent agreement. The level of disagreement ranges from 11.03 percent to 17.14 percent across the eight series. The largest difference in daily returns between the original and adjusted indices was 5.6 percent on January 12, 2009. The average daily return difference between the indices equals 0.3924 percent. The results here indicate a higher level of disagreement than in Jalbert (2012), who finds daily sign disagreement of between 10.92 to 14.71 percent for his Major Index adjusted indices and 6.99 to 9.61 percent for his Broad Index adjusted indices. The level and extent of disagreement reported here clearly indicate the potential for misleading inferences by investors observing the original indices.

Table 2: Daily Return Analysis

\begin{tabular}{lccccc}
\hline \multicolumn{1}{c}{ Series } & Total Observations & Obs. Agree & Obs. Disagree & Percent Agree & Percent Disagree \\
\hline Dow Jones Industrial Average & 5,106 & 4,264 & 842 & 83.51 & 16.49 \\
Dow Jones Transportation & 5,106 & 4,524 & 582 & 88.60 & 11.40 \\
Dow Jones Utilities & 5,106 & 4,335 & 771 & 84.90 & 15.10 \\
S\&P 500 & 5,106 & 4,284 & 822 & 83.90 & 16.10 \\
NASDAQ 100 & 5,106 & 4,543 & 563 & 88.97 & 11.03 \\
Russell 3000 & 5,106 & 4,296 & 810 & 84.14 & 15.86 \\
Russell 1000 & 5,106 & 4,300 & 806 & 84.21 & 15.79 \\
NYSE Composite & 5,106 & 4,231 & 875 & 82.86 & 17.14 \\
\hline
\end{tabular}

This table shows the daily return analysis. We computed continuously compounded daily returns $\left(\mathrm{CCR}_{\mathrm{t}}\right)$ using the formula: $\mathrm{CCR}_{\mathrm{t}}=$ $\ln \left(\frac{\text { Index Level }_{t}}{\text { Index Level } t-1}\right)$. The column labeled Total Observations indicates the number of daily return observations. The column labeled Obs. Agree indicate the number of daily observations where the original and adjusted series agree on the return sign. In this case, both series may indicate a positive or negative return. The column labeled Obs. Disagree indicates the number of daily observations where the original and adjusted series disagree on the return sign. In this case, one series indicates a positive return while the other series indicates a negative return. The columns labeled Percent Agree and Percent Disagree indicate the percentage of all daily returns with index agreement and disagreement respectively.

The analysis continues by computing annualized returns using calculations analogous to Equation 3. Table 3 shows results for the Dollar Index and each pairwise stock index combination. The average annual difference between the original and adjusted index returns is 6.848 percent. The largest return difference occurs in 2003 at 15.851 percent. The smallest difference occurs in 2012 at 0.575 percent. Given average historical annual U.S. Stock returns of about 10 percent, the differences identified here are certainly meaningful for investors.

Table 3: Annual Index Returns

\begin{tabular}{cccccccccc}
\hline YEAR & DXY & DJI & DJIA & DJT & DJTA & DJU & DJUA & SP500 & SP500A \\
\hline 1993 & 4.881 & 12.859 & 17.595 & 19.561 & 24.298 & 3.678 & 8.414 & 6.817 & 11.554 \\
1994 & -8.746 & 2.118 & -6.628 & -19.160 & -27.907 & -23.367 & -32.113 & -1.551 & -10.297 \\
1995 & -4.577 & 28.857 & 24.279 & 30.858 & 26.280 & 21.651 & 17.074 & 29.350 & 24.772 \\
1996 & 3.888 & 23.122 & 27.010 & 12.985 & 16.872 & 3.114 & 7.002 & 18.452 & 22.339 \\
1997 & 12.296 & 20.409 & 32.706 & 36.721 & 49.017 & 16.071 & 28.367 & 27.009 & 39.305 \\
1998 & -5.656 & 14.928 & 9.271 & -3.347 & -9.003 & 13.424 & 7.767 & 23.640 & 17.984 \\
1999 & 7.860 & 22.491 & 30.351 & -5.620 & 2.240 & -9.725 & -1.865 & 17.836 & 25.696 \\
2000 & 7.277 & -6.366 & 0.911 & -1.033 & 6.244 & 37.469 & 44.747 & -10.691 & -3.413 \\
2001 & 6.416 & -7.369 & -0.953 & -10.988 & -4.571 & -33.804 & -27.387 & -13.975 & -7.559 \\
2002 & -13.713 & -18.348 & -32.061 & -13.354 & -27.068 & -31.190 & -44.903 & -26.613 & -40.326 \\
2003 & -15.851 & 22.572 & 6.721 & 26.373 & 10.522 & 21.540 & 5.689 & 23.413 & 7.561 \\
2004 & -7.239 & 3.099 & -4.140 & 23.353 & 16.114 & 22.711 & 15.471 & 8.612 & 1.373 \\
2005 & 12.013 & -0.609 & 11.404 & 9.965 & 21.978 & 19.018 & 31.031 & 2.957 & 14.970 \\
2006 & -8.525 & 15.090 & 6.565 & 8.323 & -0.202 & 12.002 & 3.477 & 12.768 & 4.244 \\
2007 & -8.771 & 6.234 & -2.537 & 0.227 & -8.544 & 15.346 & 6.575 & 3.469 & -5.302 \\
\hline
\end{tabular}


Table 3 cont.

\begin{tabular}{|c|c|c|c|c|c|c|c|c|c|}
\hline 2008 & 5.653 & -41.305 & -35.652 & -25.631 & -19.978 & -36.208 & -30.556 & -48.590 & -42.937 \\
\hline 2009 & -4.139 & 17.243 & 13.105 & 14.758 & 10.619 & 7.092 & 2.954 & 21.070 & 16.931 \\
\hline 2010 & 1.454 & 10.457 & 11.910 & 21.967 & 23.420 & 1.739 & 3.192 & 12.029 & 13.483 \\
\hline 2011 & 1.545 & 5.381 & 6.926 & -1.720 & -0.175 & 13.749 & 15.294 & -0.003 & 1.542 \\
\hline 2012 & -0.575 & 7.005 & 6.430 & 5.562 & 4.987 & -2.526 & -3.101 & 12.580 & 12.005 \\
\hline 2013 & 2.879 & 12.609 & 15.488 & 14.645 & 17.524 & 14.410 & 17.289 & 10.800 & 13.679 \\
\hline YEAR & NDX & NDXA & RUA & RUAA & RUI & RUIA & NYA & NYAA & \\
\hline 1993 & 10.054 & 14.790 & 7.824 & 12.561 & 7.073 & 11.810 & 7.562 & 12.299 & \\
\hline 1994 & 1.493 & -7.253 & -2.508 & -11.254 & -2.451 & -11.197 & -3.192 & -11.939 & \\
\hline 1995 & 35.442 & 30.865 & 28.955 & 24.378 & 29.594 & 25.016 & 27.239 & 22.662 & \\
\hline 1996 & 35.445 & 39.333 & 17.555 & 21.442 & 17.999 & 21.887 & 17.442 & 21.329 & \\
\hline 1997 & 18.758 & 31.055 & 25.828 & 38.125 & 26.610 & 38.906 & 26.472 & 38.768 & \\
\hline 1998 & 61.681 & 56.024 & 20.149 & 14.492 & 22.413 & 16.757 & 15.318 & 9.662 & \\
\hline 1999 & 70.285 & 78.145 & 17.753 & 25.612 & 17.781 & 25.640 & 8.751 & 16.611 & \\
\hline 2000 & -45.957 & -38.679 & -8.901 & -1.623 & -9.254 & -1.977 & 1.005 & 8.283 & \\
\hline 2001 & -39.532 & -33.116 & -13.490 & -7.074 & -14.608 & -8.192 & -10.770 & -4.354 & \\
\hline 2002 & -47.131 & -60.844 & -25.894 & -39.607 & -26.056 & -39.769 & -22.096 & -35.810 & \\
\hline 2003 & 39.960 & 24.109 & 25.256 & 9.405 & 24.325 & 8.474 & 25.681 & 9.830 & \\
\hline 2004 & 9.927 & 2.688 & 9.601 & 2.362 & 9.067 & 1.828 & 11.476 & 4.237 & \\
\hline 2005 & 1.474 & 13.487 & 4.190 & 16.203 & 4.275 & 16.288 & 6.719 & 18.732 & \\
\hline 2006 & 6.569 & -1.956 & 12.806 & 4.281 & 12.525 & 4.001 & 16.435 & 7.910 & \\
\hline 2007 & 17.118 & 8.348 & 3.242 & -5.529 & 3.789 & -4.981 & 6.372 & -2.399 & \\
\hline 2008 & -54.275 & -48.622 & -48.934 & -43.281 & -49.454 & -43.801 & -52.585 & -46.932 & \\
\hline 2009 & 42.876 & 38.737 & 22.679 & 18.541 & 22.690 & 18.552 & 22.156 & 18.018 & \\
\hline 2010 & 17.580 & 19.034 & 13.760 & 15.214 & 12.989 & 14.443 & 10.294 & 11.748 & \\
\hline 2011 & 2.668 & 4.213 & -0.925 & 0.620 & -0.509 & 1.036 & -6.310 & -4.765 & \\
\hline 2012 & 15.545 & 14.970 & 13.083 & 12.508 & 13.036 & 12.461 & 12.156 & 11.581 & \\
\hline 2013 & 7.091 & 9.970 & 10.960 & 13.839 & 11.004 & 13.883 & 8.453 & 11.332 & \\
\hline
\end{tabular}

This table shows annual returns for original and adjusted indices. We compute continuously compounded annual returns $\left(\mathrm{CCR}_{\mathrm{t}}\right)$ using the formula: $\mathrm{CCR}_{\mathrm{t}}=\ln \left(\frac{\text { Index Level }_{\mathrm{t}}}{\text { Index Level }_{\mathrm{t}-1}}\right)$. DXY indicates the Dollar Index. DJI, DJT, DJU, DJIA, DJTA and DJUA indicate the original and adjusted Dow Jones Industrial, Dow Jones Transportation and Dow Jones Utilities indices respectively. SP500 and SP500A indicate the original and adjusted Standard and Poor's 500 index respectively. NDX and NDXA indicate the original and adjusted NASDAQ 100 indices respectively. RUA, RUI, RUAA and RUIA indicate the original and adjusted Russell 3000 and Russell 1000 indices respectively. NYA and NYAA indicate the original and adjusted NYSE Composite indices respectively.

Table 4 shows further analysis of the annual returns. In a manner similar to the daily return analysis, we compute the number of years with original and adjusted index, return sign agreement and disagreement. The Dow Jones Industrial Average shows the lowest agreement. The DJI return signs agree for 16 of 21 years and disagree for five of 21 years, representing a 76.19 percent agreement rate. In contrast, original and adjusted returns on the Dow Jones Utilities Index show perfect agreement. Jalbert (2012) found agreement levels of 82.05 for the DJI, indicating the adjusted DJI index developed here differs more from its original form than the adjusted indexes developed in Jalbert (2012).

Table 4: Annual Return Analysis

\begin{tabular}{lccccc}
\hline \multicolumn{1}{c}{ Index } & Observations & Sign Agreement & $\begin{array}{c}\text { Sign } \\
\text { Disagreement }\end{array}$ & $\begin{array}{c}\text { Percentage } \\
\text { Agreement }\end{array}$ & $\begin{array}{c}\text { Percentage } \\
\text { Disagreement }\end{array}$ \\
\hline Dow Jones Industrial & 21 & 16 & 5 & 76.19 & 23.81 \\
Dow Jones Transportation & 21 & 17 & 4 & 80.95 & 19.05 \\
Dow Jones Utilities & 21 & 21 & 0 & 100 & 0 \\
S\&P 500 & 21 & 19 & 2 & 90.48 & 9.52 \\
NASDAQ 100 & 21 & 19 & 2 & 90.48 & 9.52 \\
Russell 3000 & 21 & 19 & 2 & 90.48 & 9.52 \\
Russell 1000 & 21 & 19 & 2 & 90.48 & 9.52 \\
NYSE Composite & 21 & 20 & 1 & 95.24 & 4.76 \\
\hline
\end{tabular}

This table shows the number and percentage of annual returns where the sign of the adjusted returns agree and disagree with the sign of the original index returns. 
Table 5 provides a correlation analysis. If stock and currency indices display perfect positive correlation, Dollar Index adjusted indices would make little sense. We compute correlation between each original and adjusted series combination. Column 2 shows correlation for daily index levels. The results show correlation between 0.8813 for the Dow Jones Utilities and 0.9562 for the NASDAQ 100. Columns 3 and 4 show correlations between index returns. Column 3 shows daily return correlations between 0.9035 for the NYSE composite and 0.9631 for the NADDAQ 100. Column 4 shows annual return correlations between 0.8850 for the Dow Jones industrial average and 0.9713 for the NASDAQ 100. Jalbert (2012) found substantially higher correlation levels for the index levels with correlation between 0.9497 and 0.9807 . Jalbert (2012) results also show more variation in the daily return correlation across the indices. While the correlations presented here are relatively high, Dollar Index adjustments offer the potential for improved insights.

Table 5: Correlation Analysis

\begin{tabular}{lccc}
\hline \multicolumn{1}{c}{ Index } & Daily Index Levels & Daily Index Returns & Annual Index Returns \\
\hline Dow Jones Industrial & 0.8925 & 0.9037 & 0.8850 \\
Dow Jones Transportation & 0.9360 & 0.9433 & 0.9029 \\
Dow Jones Utilities & 0.8813 & 0.9047 & 0.9290 \\
S\&P 500 & 0.8943 & 0.9118 & 0.9136 \\
NASDAQ 100 & 0.9562 & 0.9631 & 0.9713 \\
Russell 3000 & 0.8914 & 0.9127 & 0.9123 \\
Russell 1000 & 0.8940 & 0.9246 & 0.9146 \\
NYSE Composite & 0.8973 & 0.9035 & 0.9073 \\
\hline
\end{tabular}

This table shows the correlation between original and adjusted indices. The column labeled Daily Index Levels shows correlation between the original and adjusted daily index levels. The columns labeled Daily Index Returns and Annual Index Returns show the correlation between returns.

Next, we compute daily return distribution statistics. Table 6 shows the results. Panel A shows results for the original indices. Panel B shows results for the adjusted indices. For each series, we compute the mean, standard deviation skewness and kurtosis. In addition, we compute the Cramer-von Mises test as modified by Anderson (1962) for distribution normality. The results show modest and large distribution differences. For example, the standard deviation for the original Dow Jones Industrial Average is 7.6 percent larger (13.206 versus 7.644) than for the adjusted series. The normality test rejects the normal distribution for each original and adjusted distribution.

Table 6: Daily Return Distribution Statistics

\begin{tabular}{|c|c|c|c|c|c|}
\hline Index & Mean & Std. Dev. & Skewness & Kurtosis & Normality \\
\hline \multicolumn{6}{|c|}{ Panel A: Unadjusted Index Returns } \\
\hline Dow Jones Industrial & 0.00030 & 0.0114 & -0.1637 & 8.114 & $13.206^{* * *}$ \\
\hline Dow Jones Transportation & 0.00028 & 0.0153 & -0.3526 & 5.837 & $7.030 * * *$ \\
\hline Dow Jones Utilities & 0.00017 & 0.0116 & -0.0184 & 11.715 & $12.377 * * *$ \\
\hline S\&P 500 & 0.00025 & 0.0121 & -0.2382 & 8.416 & $15.464 * * *$ \\
\hline NASDAQ 100 & 0.00041 & 0.0188 & 0.0855 & 5.149 & $11.444 * * *$ \\
\hline Russell 3000 & 0.00026 & 0.0122 & -0.2875 & 8.181 & $15.804 * * *$ \\
\hline Russell 1000 & 0.00026 & 0.0132 & -0.4179 & 10.663 & $21.587 * * *$ \\
\hline NYSE Composite & 0.00025 & 0.0118 & -0.3871 & 10.429 & $18.333 * * *$ \\
\hline \multicolumn{6}{|c|}{ Panel B: Dollar Index Adjusted Index Returns } \\
\hline Dow Jones Industrial & 0.00027 & 0.0123 & -0.2572 & 5.148 & $7.644 * * *$ \\
\hline Dow Jones Transportation & 0.00026 & 0.0159 & -0.3952 & 6.054 & $4.904 * * *$ \\
\hline Dow Jones Utilities & 0.00015 & 0.0124 & -0.1550 & 7.323 & $7.374 * * *$ \\
\hline S\&P 500 & 0.00023 & 0.0128 & -0.2457 & 5.236 & $8.777 * * *$ \\
\hline NASDAQ 100 & 0.00038 & 0.0196 & 0.0991 & 5.079 & $9.873 * * *$ \\
\hline Russell 3000 & 0.00024 & 0.0129 & -0.2818 & 5.143 & $8.616^{* * *}$ \\
\hline Russell 1000 & 0.00024 & 0.0138 & -0.3098 & 7.280 & $12.946^{* * *}$ \\
\hline NYSE Composite & 0.00023 & 0.0122 & -0.3840 & 6.536 & $10.059 * * *$ \\
\hline
\end{tabular}

This table shows daily return distribution statistics. We compute continuously compounded annual returns $\left(\mathrm{CCR}_{\mathrm{t}}\right)$ using the formula: $\mathrm{CCR}_{\mathrm{t}}=$ $\ln \left(\frac{\text { Index Level }_{\mathrm{t}}}{\text { Index Level }_{\mathrm{t}-1}}\right)$. The Cramer-von Mises test as modified by Anderson (1962) identifies deviations from normality. $* * *$ indicates significance at the 1 percent level.

The results in Table 6 show the individual return series do not follow a normal distribution. Jalbert (2012) also identified this phenomenon. However, primary interest lies in the extent to which the pairwise series have 
different distributions. To determine the extent to which the original and adjusted indices have different distributions, we compute three test statistics. The Welch F-test (1951) identifies different means and the MannWhitney (1947) identifies median differences. The Brown and Forsythe (1974) test identifies differences in variance. The results, presented in Table 7, show no significant differences between the mean and median returns of the original and adjusted series. However, the series have significantly different variance. The results from Table 6 show the adjusted series have higher variance than the original series. Jalbert (2012) also found distributions of original and adjusted series differ. Combined, these findings suggest that empirical tests based on original series might underestimate the wealth risk an investor faces. Thus, tests of the Capital Asset Pricing Model (Sharpe, 1964) and other pricing models using original indices will produce misleading results.

Table 7: Daily Return Distribution Difference Tests

\begin{tabular}{lccc}
\hline \multicolumn{1}{c}{ Index } & Mean & Median & Variance \\
\hline Dow Jones Industrial & 0.0096 & 0.2005 & $35.34 * * *$ \\
Dow Jones Transportation & 0.0056 & 0.1006 & $9.277^{* * *}$ \\
Dow Jones Utilities & 0.0094 & 0.1317 & $25.24 * * *$ \\
S\&P 500 & 0.0087 & 0.1199 & $27.72^{* * *}$ \\
NASDAQ 100 & 0.0037 & 0.1917 & $6.401^{* *}$ \\
Russell 3000 & 0.0086 & 0.0799 & $27.66^{* * *}$ \\
Russell 1000 & 0.0074 & 0.0432 & $22.10^{* * *}$ \\
NYSE Composite & 0.0094 & 0.0366 & $18.19^{* * *}$ \\
\hline
\end{tabular}

This table shows daily return distribution, difference test results. Each test compares returns on the original index to returns on the Dollar Index adjusted index. The Welch F-test (1951) test identifies significant differences in means and the Mann-Whitney (1947) test identifies differences between medians. The Brown and Forsythe (1974) test identifies differences in variance. The figure in each cell is the test statistic value. ***, and $* *$ indicate significance at the 1 and 5 percent levels respectively.

The final analysis examines the amount of wealth change variance explained by original index changes and Dollar Index changes. We define wealth change to be the daily change in the adjusted index, which reflects both changes in the original index and changes in the dollar value. We estimate three equations to determine explanatory power. The first equation identifies the amount of wealth changes explained by changes in the original index.

$D A S_{t}-D A S_{t-1}=\beta_{1} *\left(O I_{t}-O I_{t-1}\right)+\varepsilon_{t}$

The term $\beta_{1}$ is the ordinary least squares regression (OLS) coefficient and $\varepsilon_{t}$ is a random error term. The careful reader will notice the model does not include an intercept term. This omission is intentional to focus directly on the independent variable explanatory power. Table 8, Panel A shows the results. Each regression coefficient is statistically significant. The highest R2 occurs for the NASDAQ 100 index at 0.9360 indicating that original index changes explain 93.60 percent of daily wealth variation. The lowest R2 value is 0.7873 for the NYSE composite.

Table 8: Regression Analysis on Dollar Index Adjusted Return Indices

\begin{tabular}{|c|c|c|c|c|c|}
\hline Dependent Variable & Unadjusted Stock Index Change & T-statistic & $\begin{array}{c}\text { Dollar Index } \\
\text { Change }\end{array}$ & T-statistic & $\mathbf{R 2}$ \\
\hline \multicolumn{6}{|l|}{ Panel A: Single Regression } \\
\hline Dow Jones Industrial & 0.8825 & $138.00 * * *$ & & & 0.7885 \\
\hline Dow Jones Transportation & 0.8291 & $181.26 * * *$ & & & 0.8655 \\
\hline Dow Jones Utilities & 0.8495 & $140.96 * * *$ & & & 0.7956 \\
\hline S\&P 500 & 0.8970 & $146.09 * * *$ & & & 0.8069 \\
\hline NASDAQ 100 & 1.0320 & $273.25 * * *$ & & & 0.9360 \\
\hline Russell 3000 & 0.8811 & $145.62 * * *$ & & & 0.8059 \\
\hline Russell 1000 & 0.8786 & $153.81 * * *$ & & & 0.8225 \\
\hline NYSE Composite & 0.8065 & $136.25 * * *$ & & & 0.7873 \\
\hline \multicolumn{6}{|l|}{ Panel B: Single Regression } \\
\hline Dow Jones Industrial & & & 87.63 & $29.94 * * *$ & 0.1492 \\
\hline Dow Jones Transportation & & & 26.26 & $19.39 * * *$ & 0.0684 \\
\hline Dow Jones Utilities & & & 2.661 & $25.38 * * *$ & 0.1119 \\
\hline S\&P 500 & & & 9.980 & $27.98 * * *$ & 0.1328 \\
\hline NASDAQ 100 & & & 18.67 & $15.99 * * *$ & 0.0476 \\
\hline Russell 3000 & & & 5.505 & $27.17 * * *$ & 0.1262 \\
\hline
\end{tabular}


Table 8 cont.

\begin{tabular}{|c|c|c|c|c|c|}
\hline Russell 1000 & & & 5.263 & $26.00 * * *$ & 0.1168 \\
\hline NYSE Composite & & & 44.44 & $23.05 * * *$ & 0.0940 \\
\hline \multicolumn{6}{|c|}{ Panel C: Multiple Regression } \\
\hline Dow Jones Industrial & 0.8993 & $355.46 * * *$ & 95.82 & $166.03 * * *$ & 0.9670 \\
\hline Dow Jones Transportation & 0.8494 & $411.89 * * *$ & 32.92 & $141.87 * * *$ & 0.9730 \\
\hline Dow Jones Utilities & 0.8848 & $370.83 * * *$ & 3.316 & $166.51 * * *$ & 0.9682 \\
\hline S\&P 500 & 0.9135 & $368.17 * * *$ & 11.01 & $161.89 * * *$ & 0.9685 \\
\hline NASDAQ 100 & 1.0276 & $438.47 * * *$ & 16.97 & $90.33 * * *$ & 0.9754 \\
\hline Russell 3000 & 0.9015 & $365.48 * * *$ & 6.239 & $160.29 * * *$ & 0.9678 \\
\hline Russell 1000 & 0.8951 & $373.81 * * *$ & 5.894 & $154.94 * * *$ & 0.9689 \\
\hline NYSE Composite & 0.8588 & $372.83 * * *$ & 62.59 & $170.90 * * *$ & 0.9679 \\
\hline
\end{tabular}

This table shows regression results for Equations 4, 5 and 6. Panel A reports estimation results for Equation 4, specified: $\mathrm{DAS}_{\mathrm{t}}-\mathrm{DAS}_{\mathrm{t}-1}=\beta_{1} *$ $\left(\mathrm{OI}_{\mathrm{t}}-\mathrm{OI}_{\mathrm{t}-1}\right)+\varepsilon_{\mathrm{t}}$. DAS indicates the dollar adjusted stock index. OI indicates the original index. Panel B reports estimation results for Equation 5, specified: $\mathrm{DAS}_{\mathrm{t}}-\mathrm{DAS}_{\mathrm{t}-1}=\beta_{1} *\left(\mathrm{DI}_{\mathrm{t}}-\mathrm{DI}_{\mathrm{t}-1}\right)+\varepsilon_{\mathrm{t}}$. DI indicates the Dollar Index. Panel C reports estimation results for Equation 6, specified: $\mathrm{DAS}_{\mathrm{t}}-\mathrm{DAS}_{\mathrm{t}-1}=\beta_{1} *\left(\mathrm{OI}_{\mathrm{t}}-\mathrm{OI}_{\mathrm{t}-1}\right)+\beta_{2} *\left(\mathrm{DI}_{\mathrm{t}}-\mathrm{DI}_{\mathrm{t}-1}\right)+\varepsilon_{\mathrm{t}}$. *** indicates significance at the 1 percent level.

The second equation determines the extent that daily changes in the Dollar Index explain daily changes in the adjusted index.

$D A S_{t}-D A S_{t-1}=\beta_{1} *\left(D I_{t}-D I_{t-1}\right)+\varepsilon_{t}$

Table 8, Panel B presents the Equation 5 estimation results. Each regression coefficient is significant at the one percent level. The regression R2 statistics range in value from 0.0476 to 0.1492 . These results indicate that daily Dollar Index changes explain between 4.76 and 14.92 percent of daily changes in the respective adjusted index. The findings here indicate currency value changes explain more of the wealth change than the results reported by Jalbert (2012). Recall that Jalbert (2012) found that currency changes explain as much as 8.44 percent of wealth changes.

The third estimation equation considers the combined effects of original index changes and Dollar Index changes on investor wealth changes. Equation 6 captures both wealth effects.

$D A S_{t}-D A S_{t-1}=\beta_{1} *\left(O I_{t}-O I_{t-1}\right)+\beta_{2} *\left(D I_{t}-D I_{t-1}\right)+\varepsilon_{t}$

Table 8, Panel C presents the Equation 6 estimation results. Like the single regression coefficients, each regression coefficient is significant at the one percent level. The R2 statistics range from 0.9670 to 0.9754 .

The combined results from Table 8, clearly show that examining original indices without considering dollar value changes ignores a considerable component of wealth changes. The indices developed here provide a more accurate picture of wealth change and thus represent a considerable advance over previously available products.

\section{CONCLUDING COMMENTS}

This paper develops a series of new stock indices. The indices consider changes in stock values and changes in the underlying currency value. This measure captures total wealth changes and thus represents an advance over traditional indices. The indices here extend the work of Jalbert (2012) by extending the analysis to include nearly two years of recent data and using a different measure of the dollar value. The Dollar Index used here has at least three advantages over the Federal Reserve indices used by Jalbert, 2012. The Dollar Index has intraday quotations, options availability, futures contract availability and is widely reported in the press.

The paper examines daily stock index data and Dollar Index data from 1993-2013. The results show the original and adjusted series follow different patterns. The daily returns on the original and adjusted indices have different signs on 11 to 17 percent of all observation days. Adjusted and unadjusted annual returns differ by as little as 0.575 percent in 2012 and as much as 15.851 percent in 2003. These differences clearly indicate that investors observing unadjusted indexes in isolation receive an inaccurate picture of wealth changes. Daily return distribution, difference tests show the adjusted indices have significantly higher variance than the original indices. This finding 
is particularly important for empirical tests of pricing models that attempt to model the relationship between risk and return. Finally, we complete regression analysis to determine the proportion of wealth change attributable to the original stock index changes and Dollar Index changes. The results attribute as much as 14.92 percent of wealth changes to currency value changes. This result compares to the result of Jalbert (2012) who found currency value changes explained up to 8.44 percent of wealth changes.

The analysis here represents a preliminary analysis of currency value adjusted stock indices. Considerable additional work remains to investigate the usefulness and impact of these indices. The results here are limited to U.S. dollar denominated indices. Further research can develop similar indices that track the value of international indices. Future studies might use additional statistical techniques to model time-series properties of the indices.

\section{AUTHOR INFORMATION}

Terrance Jalbert is Professor of Finance at the University of Hawaii at Hilo. He has also served as an arbitrator for the Financial Industry Regulatory Authority. His research appears in Journals that include, International Journal of Finance, Advances in Taxation, Financial Services Review, Journal of Applied Business Research, Journal of Personal Finance, Journal of Emerging Markets, The International Journal of Business and Finance Research and Journal of Accounting Education. E-mail: jalbert@ hawaii.edu

\section{REFERENCES}

1. Alvarez-Ramirez, J., \& Rodriguez, E. (2011). Long-term recurrence patterns in the late 2000 economic crisis: Evidences from entropy analysis of the Dow Jones index. Technological Forecasting and Social Change, 78(8), 1332-1344.

2. Anderson, T.W. (1962). on the distribution of the two-sample Cramer-von Mises criterion. The Annals of Mathematical Statistics, 33(3), 1148-1159.

3. Bureau of Consular Affairs, U.S. Department of State. (2013). Who we are and what we do: Consular affairs by the numbers. May, Downloaded 06/18/2013 from http://travel.state.gov/pdf/ca_fact_sheet.pdf

4. Bureau of Resource Management, U.S. Department of State. (2004). FY 2005 performance summary (the plan). February, Downloaded 06/18/2013 from www.state.gov/s/d/rm/rls/perfplan/2005/html/29269.htm

5. Beneish, M., \& Gardner, J. (1995). Information costs and liquidity effects from changes in the Dow Jones industrial average list. Journal of Financial and Quantitative Analysis, 30, 135-157.

6. Black, F., \& Scholes, M. (1973). The pricing of options and corporate liabilities. Journal of Political Economy, 81(May/June), 637-659.

7. Bollerslev, T., Engle, R. F., \& Wooldridge, J.M. (1988). A capital asset pricing model with time varying covariances. Journal of Political Economy, 96, 116-131.

8. Breen, W., Glosten, L. R., \& Jagannathan, R. (1989). Economic significance of predictable variations in stock index returns. The Journal of Finance, XLIV(5, December), 1177-1189.

9. Brown, M. B. \& Forsythe, A. B. (1974). Robust tests for equality of variances. Journal of the American Statistical Association, 69, 364-367.

10. Chen, H., Noronha, G., \& Singal, V. (2006). Index changes and losses to index fund investors. Financial Analysts Journal, 62(4), 31-47.

11. Christie, A. A. (1982). The stochastic behavior of common stock variances: Value, leverage and interest rate effects. Journal of Financial Economics, 10, 407-432.

12. Donaldson, R. G., \& Kim H. Y. (1993). Price barriers in the Dow Jones industrial average. Journal of Financial and Quantitative Analysis, 28(3, September), 313-330.

13. French and Roll (1986). Stock return variances: The arrival of information and the reaction of traders. Journal of Financial Economics, 17, 5-26.

14. Ferreira, T. A. E., Vasconcelos, G. C., \& Adeodato, P. J. L. (2008). A new intelligent system methodology for time series forecasting with artificial neural networks. Neural Process Letters, 28, 113-129.

15. Hora, S., \& Jalbert, T. (2006). The Dow Jones industrial average in the twentieth century - Implications for option pricing. Academy of Accounting and Financial Studies Journal, 10(3), 17-40.

16. Jalbert, T. (2012). The performance of currency value adjusted stock indices. The Journal of Index Investing, 3(2), 34-48. 
17. Jankovskis, P. (2002). The impact of Russell 2000 rebalancing on small-cap performance. The Journal of Investment Consulting, 5(2), 23-29.

18. Jarque, C. M., \& Bera, A. K. (1980). Efficient Tests for normality, homoscedasticity and serial independence of regression residuals. Economics Letters, 6(3), 255-259

19. Koch, C. (2013). What is the DXY index. Ezine Articles, November 22, downloaded 06/18/2013 from http://ezinearticles.com/?What-Is-the-DXY-Dollar-Index?\&id=5381416

20. Lakonishok, J., \& Smidt, S. (1988). Are seasonal anomalies real? A ninety-year perspective. The Review of Financial Studies, 1(4), 403-425.

21. Lauterbach, B. (1989). Consumption volatility, production volatility, spot rate volatility and the returns on treasury bills and bonds. Journal of Financial Economics, 24(1), 155-179.

22. Liu, S. (2011). The price effects of index additions: A new explanation. Journal of Economics and Business, 63, 152-165.

23. Mann, H. B., \& Whitney, D. R. (1947). On a test of whether one of two random variables is stochastically larger than the other. Annals of Mathematical Statistics, 18(1), 50-60.

24. Martens, M., van Dijk, D., \& de Pooter, M. (2009). Forecasting S\&P 500 volatility: Long memory, level shifts, leverage effects, day-of-the-week seasonality and macroeconomic announcements. International Journal of Forecasting, 25(2, April-June) 282-303.

25. Merton, R.C. (1980). On estimating the expected return on the market: an exploratory investigation. Journal of Financial Economics, 8, 323-361.

26. Opong, K. K., Mulholland, G., Fox, A. F., \& Farahmand, K. (1999). The behavior of some UK equity indexes: An application of hurst and BDS tests. Journal of Empirical Finance, 6, 267-282.

27. Sharpe, W. F. (1964). Capital asset prices: A theory of market equilibrium under conditions of risk. Journal of Finance, 19(3), 425-442.

28. Shleifer, A. (1986). Do demand curves for stocks slope down? Journal of Finance, 41, 579-590.

29. Taylor, N. (2007). Á new econometric model of index arbitrage. European Financial Management, 13(1), 159-183.

30. Welch, B. L. (1951). On the comparison of several mean values: An alternative approach. Biometrika, 38, 330-336.

31. Wong, J. C., Lian, H., \& Cheong, S. A. (2009). Detecting macroeconomic phases in the Dow Jones industrial average time series. Physica A: Statistical Mechanics and its Applications, 388(21, November), 4635-4645. 
NOTES 